\title{
Differential placental methylation and expression of VEGF, FLT-1 and KDR genes in human term and preterm preeclampsia
}

Deepali P Sundrani ${ }^{1 \dagger}$, Umakar S Reddy $^{3 \dagger}$, Asmita A Joshi ${ }^{1}$, Savita S Mehendale ${ }^{2}$, Preeti M Chavan-Gautam', Anandwardhan A Hardikar ${ }^{4}$, Giriraj R Chandak ${ }^{3}$ and Sadhana R Joshi ${ }^{*}$

\begin{abstract}
Background: Preeclampsia, a pregnancy complication of placental origin is associated with altered expression of angiogenic factors and their receptors. Recently, there is considerable interest in understanding the role of adverse intrauterine conditions in placental dysfunction and adverse pregnancy outcomes. Since we have observed changes in placental global DNA methylation levels in preeclampsia, this study was undertaken to examine gene promoter CpG methylation and expression of several angiogenic genes.

We recruited 139 women comprising, 46 normotensive women with term delivery ( $\geq 37$ weeks), 45 women with preeclampsia delivering preterm ( $<37$ weeks) and 48 women with preeclampsia delivering at term. Expression levels and promoter $\mathrm{CpG}$ methylation of VEGF, FLT-1 and KDR genes in placentae from respective groups were determined by Taqman-based quantitative real time PCR and by the Sequenom ${ }^{\oplus}$ EpiTYPER $^{\text {TM }}$ technology respectively.
\end{abstract}

Results: We observed several differentially methylated CpG sites in the promoter regions of VEGF, FLT-1 and KDR between the normotensive and preeclampsia groups. We specifically observed hypomethylated CpGs in the promoter region and an increased expression of VEGF gene between term and preterm preeclampsia. However, mean promoter CpG methylation could not account for the higher expression of FLT-1 and KDR in preterm preeclampsia as compared to normotensive group.

Conclusions: Our data indicates altered DNA methylation patterns in the VEGF, FLT-1 and KDR genes in preeclampsia as compared to the normotensive group, which could be involved in the pathophysiology of preeclampsia. Hypomethylation of VEGF promoter and consequent upregulation of VEGF mRNA levels could be a compensatory mechanism to restore normal angiogenesis and blood flow in preterm preeclampsia. This study suggests a role of altered DNA methylation in placental angiogenesis and in determining adverse pregnancy outcomes.

\section{Background}

Preeclampsia (PE) originates in the placenta and involves inadequate cytotrophoblast invasion, maternal endothelial dysfunction and altered expression of angiogenic and antiangiogenic factors, which ultimately leads to various clinical manifestations [1]. Vasculogenesis and angiogenesis are considered to be central processes in the development

\footnotetext{
*Correspondence: srjoshi62@gmail.com

${ }^{\dagger}$ Equal contributors

'Department of Nutritional Medicine, Interactive Research School for Health Affairs, Bharati Vidyapeeth University, Pune 411043, India

Full list of author information is available at the end of the article
}

of the placenta and are mainly controlled by vascular endothelial growth factor (VEGF). Altered levels of $V E G F$ and its receptors can disrupt angiogenesis, leading to placental insufficiency and endothelial dysfunction seen in PE [2]. VEGF exerts its biological effects through two high-affinity tyrosine kinase receptors namely, vascular endothelial growth factor receptor-1 (VEGFR-1)/fms-like tyrosine kinase-1 (FLT-1), and vascular endothelial growth factor receptor-2/kinase insert domain containing receptor $(K D R)$. FLT-1 interactions with VEGF are critical for invasion and pseudo-vasculogenesis while $K D R$ is a major mediator of mitogenic and angiogenic

\section{Biomed Central}


processes that enhance permeability and endothelial survival [3].

A number of studies have examined the mRNA levels of different angiogenesis regulating factors in placentae from PE patients although results are inconsistent. Some studies report increased VEGF expression [4-7], while others report reduced expression [8-10] in preeclamptic women. Other studies found no difference in VEGF expression [11-13]. Similarly expression of FLT-1 [14-16] and $K D R[11,16,17]$ have also been examined. Very few studies have simultaneously examined the expression of VEGF and both its receptors in the human placenta in PE $[18,19]$. Further, most of the reported studies have been carried out on small sample sizes and are limited by the broad range of gestational ages.

Healthy placental development involves spatio-temporally programmed gene expression patterns and any alteration in this process may compromise placental function [20-22]. Under suboptimal uterine conditions, normal methylation of DNA is disrupted, thereby altering gene expression and preventing normal growth [23]. The placenta serves as the interface between the mother and fetus. A number of environmental factors such as diet, smoking, stress, behavior and assisted reproductive techniques have been reported to influence the methylation and expression of various genes in the human placenta as well as from other animals $[24,25]$. We have earlier observed increased homocysteine and oxidative stress levels in PE [26] and shown association of alterations in placental global DNA methylation levels with homocysteine levels and blood pressure [27]. The objective of this study was to examine the methylation of the promoters of the VEGF, FLT-1 and KDR genes and their mRNA levels in placentae from women diagnosed with PE as compared to normal pregnancies. We further investigated whether the gene expression levels were related to promoter CpG methylation levels. To the best of our knowledge, no study to date has investigated the methylation patterns of the angiogenic gene VEGF and its receptors in the human placentae in PE.

\section{Results}

\section{Maternal and neonatal characteristics}

The maternal and neonatal characteristics are given in Table 1. All the women recruited in the study had similar age, income and education. The frequency of consumption of foods rich in folic acid, vitamin $\mathrm{B}_{12}$ and omega- 3 fatty acids was similar in normotensive and both the PE groups as reported by us earlier [26,28]. The body weight and gestational age at delivery were significantly lower $(P<0.05)$ in women with PE who delivered preterm. The maternal systolic and diastolic blood pressures were significantly higher in the term and preterm PE groups compared to the normotensive group. Newborn weight was significantly reduced $(P<0.01)$ in the term $P E$ group as compared to the
Table 1 Maternal and neonatal characteristics

\begin{tabular}{|c|c|c|c|}
\hline & $\begin{array}{l}\text { Normotensive } \\
(\mathrm{n}=46)\end{array}$ & $\begin{array}{l}\text { Term PE } \\
(n=48)\end{array}$ & $\begin{array}{l}\text { Preterm PE } \\
(\mathrm{n}=45)\end{array}$ \\
\hline \multicolumn{4}{|l|}{ Maternal characteristics } \\
\hline Age, yrs & $22.9 \pm 3.2$ & $23.1 \pm 2.9$ & $23.9 \pm 4.2$ \\
\hline Weight, kg & $52.1 \pm 8.2$ & $52.0 \pm 11.2$ & $47.7 \pm 6.6^{* 1}$ \\
\hline Height, cm & $152.7 \pm 4.9$ & $152.3 \pm 7.2$ & $150.7 \pm 5.4$ \\
\hline Body mass index, $\mathrm{kg} / \mathrm{m}^{2}$ & $22.3 \pm 3.4$ & $22.4 \pm 4.8$ & $20.9 \pm 2.7$ \\
\hline Gestation, wks & $39.0 \pm 1.2$ & $38.6 \pm 1.1$ & $34.2 \pm 1.9^{* * 1}$ \\
\hline Education, grade & $9.2 \pm 4.0$ & $9.8 \pm 3.5$ & $9.4 \pm 3.9$ \\
\hline Income, Rs & $\begin{array}{l}6,191.5 \pm \\
4,524.8\end{array}$ & $\begin{array}{l}5,844.4 \pm \\
3,285.3\end{array}$ & $\begin{array}{l}6,258.5 \pm \\
5,183.0\end{array}$ \\
\hline $\begin{array}{l}\text { Systolic blood pressure, } \\
\mathrm{mmHg}\end{array}$ & $123.4 \pm 7.2$ & $\begin{array}{l}152.2 \pm \\
16.0^{* *} \\
\end{array}$ & $\begin{array}{l}154.3 \pm \\
15.8^{* *}\end{array}$ \\
\hline $\begin{array}{l}\text { Diastolic blood pressure, } \\
\mathrm{mmHg}\end{array}$ & $78.3 \pm 6.0$ & $\begin{array}{l}100.8 \pm \\
11.5^{* *}\end{array}$ & $\begin{array}{l}103.0 \pm \\
13.3^{* *}\end{array}$ \\
\hline \multicolumn{4}{|l|}{ Parity, \% } \\
\hline Nulliparous & 42.6 & 68.9 & 58.5 \\
\hline Multiparous & 57.4 & 31.1 & 41.5 \\
\hline \multicolumn{4}{|l|}{ Mode of delivery, $\%$} \\
\hline Normal delivery & 70.2 & 78.3 & 45.2 \\
\hline Caesarean section & 29.8 & 21.7 & 54.8 \\
\hline \multicolumn{4}{|l|}{ Neonatal characteristics } \\
\hline \multicolumn{4}{|l|}{ Gender of fetus, \% } \\
\hline Male & 54.3 & 51.1 & 42.9 \\
\hline Female & 45.7 & 48.9 & 57.1 \\
\hline APGAR score (1 minute) & $7.7 \pm 1.2$ & $7.6 \pm 1.2$ & $6.6 \pm 1.8^{* * 1}$ \\
\hline APGAR score (5 minute) & $8.6 \pm 0.7$ & $8.8 \pm 0.7$ & $8.1 \pm 1.0^{* * 1}$ \\
\hline Weight, kg & $2.9 \pm 0.3$ & $2.7 \pm 0.5^{* *}$ & $1.9 \pm 0.5^{* * 1}$ \\
\hline Length, cm & $48.1 \pm 2.6$ & $48.1 \pm 2.4$ & $43.8 \pm 4.4^{* * 1}$ \\
\hline Head circumference, cm & $33.9 \pm 1.3$ & $33.3 \pm 1.7$ & $30.3 \pm 3.0^{* * 1}$ \\
\hline Chest circumference, $\mathrm{cm}$ & $32.3 \pm 1.4$ & $31.7 \pm 2.1$ & $27.1 \pm 2.9^{* *}$ \\
\hline
\end{tabular}

Values given are mean $\pm \mathrm{SD}$, unless stated otherwise. $\mathrm{PE}$, preeclampsia. ${ }^{*} P<0.05$; ${ }^{* *} P<0.01$ when compared to term; ${ }^{1} P<0.01$ when compared to term PE.

normotensive group. The newborn weight, height, head circumference, chest circumference and APGAR score at 1 minute and 5 minutes were significantly lower $(P<0.01)$ in the preterm preeclampsia group compared to the normotensive and term PE groups.

\section{Promoter CpG methylation of VEGF, FLT-1 and KDR genes}

We analyzed cytosine methylation at $23 \mathrm{CpG}$ sites in the VEGF promoter region, $30 \mathrm{CpG}$ sites in the FLT-1 promoter region and $37 \mathrm{CpG}$ sites in the KDR promoter. The mean percent methylation at all CpG sites in the promoter regions of the three genes are given in Additional file 1. The mean percent methylation at the differentially methylated CpG sites in the promoter regions of the three genes are given in Table 2. The mean methylation level of the $V E G F$ promoter was significantly lower $(P<0.05)$ in the 
Table 2 Mean percent methylation levels at the differentially methylated CpG sites in the promoter region of the VEGF, FLT-1 and KDR genes

\begin{tabular}{|c|c|c|c|}
\hline \multirow{3}{*}{ CpG site } & \multicolumn{3}{|c|}{ Percent methylation (\%) } \\
\hline & \multicolumn{3}{|c|}{ Mean \pm standard error } \\
\hline & Normotensive & Term PE & Preterm PE \\
\hline \multicolumn{4}{|l|}{ VEGF } \\
\hline Mean promoter & $5.1 \pm 0.1$ & $4.9 \pm 0.1$ & $4.7 \pm 0.2^{*}$ \\
\hline CpG - 6.7 & $4.2 \pm 0.2$ & $3.7 \pm 0.2$ & $3.5 \pm 0.4^{*}$ \\
\hline CpG - 8 & $7.1 \pm 0.1$ & $6.8 \pm 0.1$ & $6.4 \pm 0.2^{* *}$ \\
\hline CpG - 14 & $4.2 \pm 0.3$ & $4.9 \pm 0.3$ & $5.2 \pm 0.4^{*}$ \\
\hline \multicolumn{4}{|l|}{$F L T-1$} \\
\hline CpG - 16 & $1.6 \pm 0.2$ & $0.8 \pm 0.2^{* *}$ & $1.2 \pm 0.2$ \\
\hline CpG - 17 & $3.2 \pm 0.1$ & $3.2 \pm 0.1$ & $2.7 \pm 0.1^{* 1}$ \\
\hline CpG - 24 & $1.1 \pm 0.1$ & $0.7 \pm 0.1^{*}$ & $0.6 \pm 0.1^{*}$ \\
\hline \multicolumn{4}{|l|}{ KDR } \\
\hline CpG - 12.13 & $4.9 \pm 0.7$ & $7.6 \pm 1.1^{*}$ & $8.2 \pm 1.1^{*}$ \\
\hline
\end{tabular}

Values given are mean $\pm \mathrm{SE}$. PE, preeclampsia. ${ }^{*} P<0.05 ;{ }^{* *} P<0.01$ compared to term; ${ }^{1} P<0.05$ compared to term PE.

preterm PE group compared to the normotensive group. The mean methylation at the CpG site $6.7(P<0.05)$ and CpG site $8(P<0.01)$ was significantly reduced, whereas that at $\mathrm{CpG}$ site 14 was significantly higher $(P<0.05)$ in the preterm $\mathrm{PE}$ group compared to the normotensive group (Figure 1). The mean methylation level of the
FLT-1 gene promoter was similar between the groups. The mean methylation at $\mathrm{CpG}$ site 16 in the FLT-1 promoter region was significantly reduced $(P<0.01)$ in the term $P E$ group as compared to the normotensive group, while mean methylation at $\mathrm{CpG}$ site 17 was significantly reduced $(P<0.05)$ in the preterm $P E$ group compared to the normotensive group. Further mean methylation at the CpG site 24 was significantly reduced $(P<0.05)$ in both the term and the preterm PE group compared to the normotensive group (Figure 2). There was no significant difference in mean methylation level of the $K D R$ gene promoter between the three groups. We observed significantly higher mean methylation at CpG site 12.13 in the $K D R$ gene promoter region in term $\mathrm{PE}(P<0.05)$ and preterm PE $(P<0.01)$ group compared to the normotensive group (Figure 3). Further, several transcription factor binding sites were predicted in the promoter region of $V E G F$, FLT-1 and KDR genes (Additional file 2).

VEGF, FLT-1, and KDR gene expression levels in placenta The placental gene expression levels of $V E G F$ were significantly lower in the term PE group than in the normotensive group $(P<0.05)$, while the levels were significantly higher (1.6-fold) in the preterm PE group compared to the normotensive group. The gene expression levels of FLT-1 and $K D R$ were comparable in the normotensive and term PE groups but were higher (1.9-fold for FLT-1 and 3.0-fold
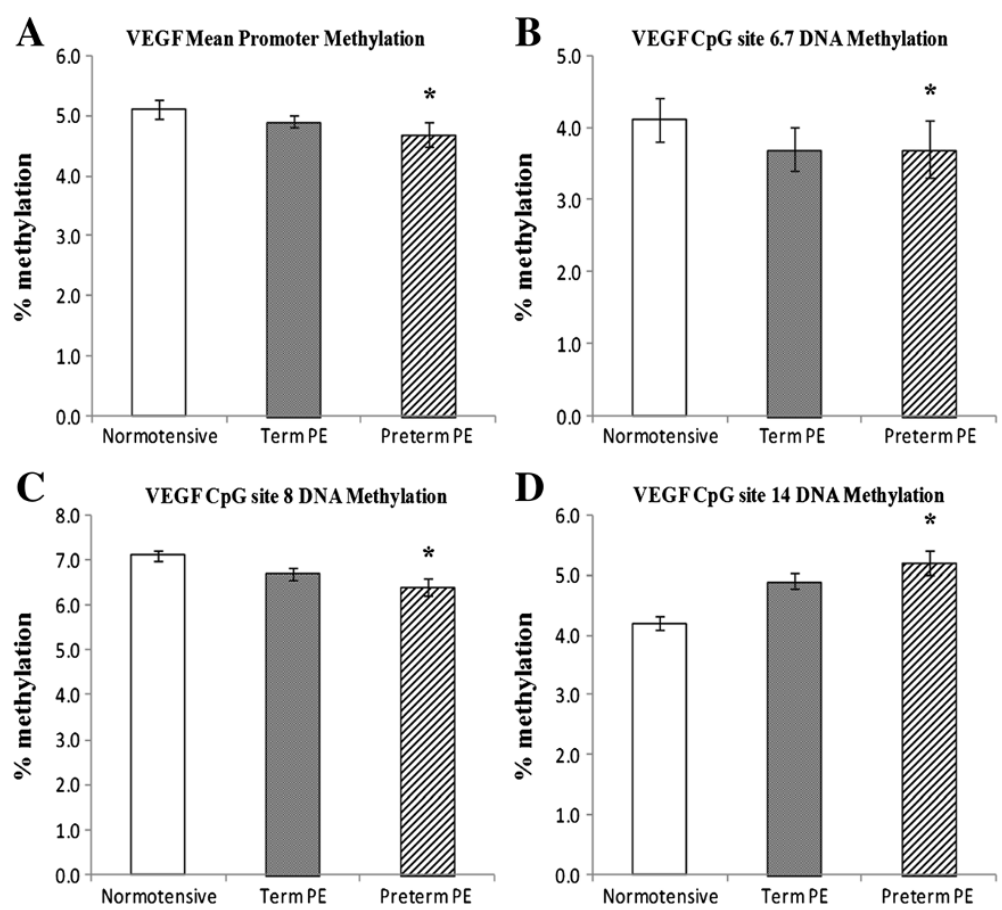

Figure 1 Mean promoter methylation levels and differentially methylated sites in the VEGF promoter: (A) VEGF Mean Promoter; (B) VEGF CpG site 6.7; (C) VEGF CpG site 8; (D) VEGF CpG site 14. ${ }^{*} P<0.05$ compared to normotensive group. PE, preeclampsia. 

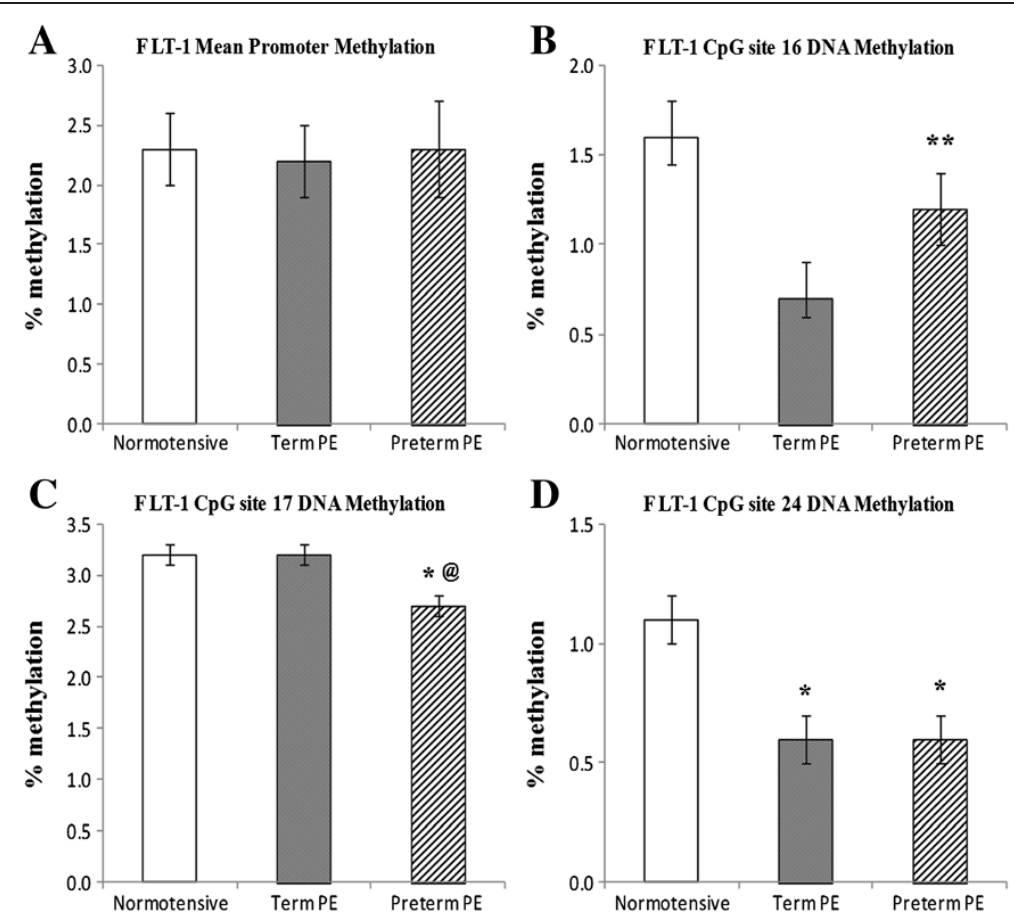

Figure 2 Mean promoter methylation levels and differentially methylated sites in the FLT-1 promoter: (A) FLT-1 Mean Promoter; (B) FLT-1 CpG site 16; (C) FLT-1 CpG site 17; (D) FLT-1 CpG site 24. ${ }^{*} P<0.05$ and ${ }^{* *} P<0.01$ compared to normotensive group; ${ }^{\circledR} P<0.05$ compared to the term PE group. PE, preeclampsia.

for $K D R)$ in the preterm PE group compared to the term PE $(P<0.05$ for $F L T-1$ and $P<0.01$ for $K D R)$ and the normotensive group $(P<0.01)$ (Figure 4$)$.

\section{Association between $\mathrm{CpG}$ methylation and gestation}

Mean promoter methylation of the VEGF gene was negatively ( $\mathrm{n}=24, r=-0.461, P=0.018)$ associated with gestation in the term PE group but not in the normotensive and preterm PE groups. Further CpG site 6.7 in the $V E G F$ promoter region was negatively associated with both the term PE ( $\mathrm{n}=24, r=-0.399, P=0.044)$ and preterm PE gestations $(\mathrm{n}=19, \mathrm{r}=-0.463, P=0.034)$. Mean promoter methylation in the FLT-1 gene was not associated with gestation in any of the groups. However, CpG site 16 showed a positive association with preterm $\mathrm{PE}$ gestation $(\mathrm{n}=30, r=0.420, P=0.020)$. There were no associations between methylation and gestation in the KDR gene promoter region.

\section{Associations between $\mathrm{CpG}$ methylation and gene expression}

The mean methylation at CpG site 6.7 in the VEGF promoter region was positively associated with $V E G F$ gene expression levels in the term PE group $(\mathrm{n}=36, r=0.331$, $P=0.049$ ). The mean methylation at CpG site 16 in the FLT-1 promoter region was negatively associated with
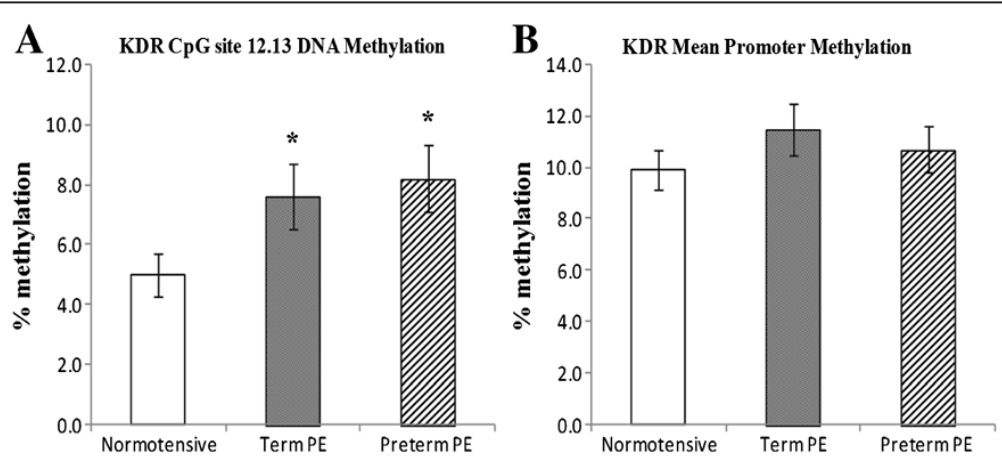

Figure 3 Mean promoter methylation levels and differentially methylated sites in the KDR promoter: (A) KDR CpG site 12.13; (B) KDR Mean Promoter. ${ }^{*} P<0.05$ and ${ }^{*} P<0.01$ as compared to normotensive group. PE, preeclampsia. 

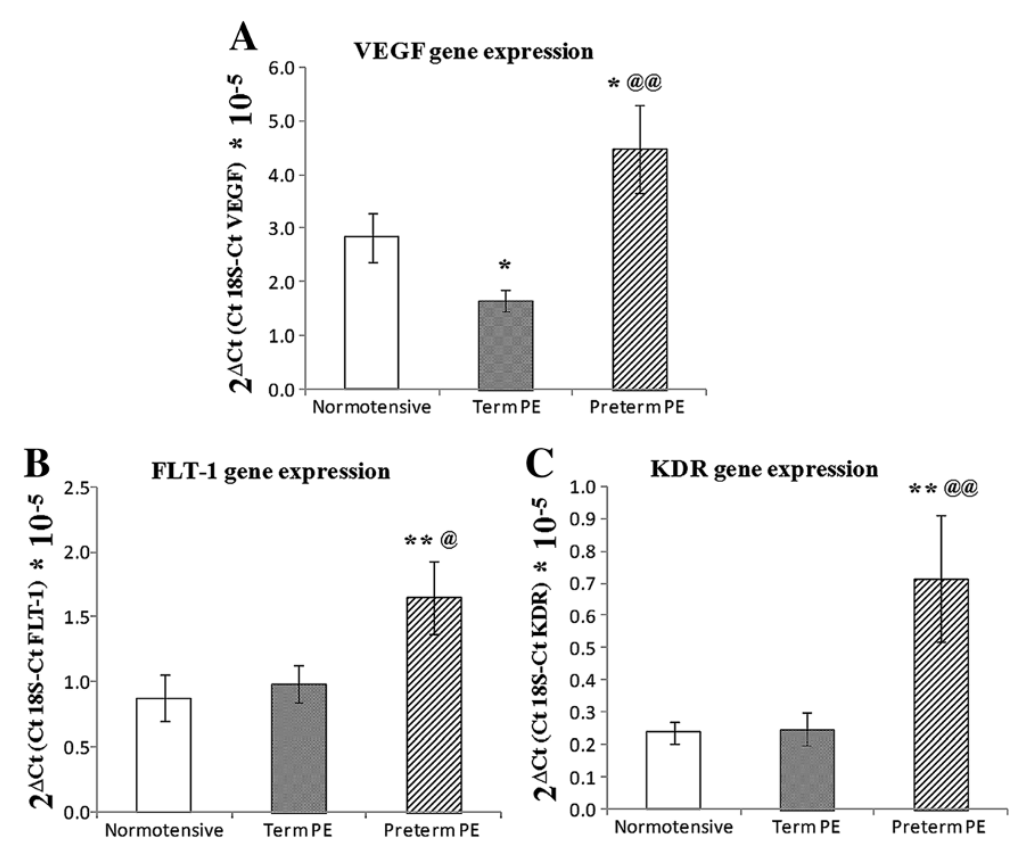

Figure 4 Gene expression levels in normotensive and preeclamptic groups: (A) VEGF Gene Expression; (B) FLT-1 Gene Expression; (C) KDR Gene Expression. ${ }^{*} P<0.05$ and ${ }^{* *} P<0.01$ when compared to normotensive group; ${ }^{@} P<0.05$ and $@ @ P<0.01$ when compared to the Term PE group. PE, preeclampsia.

FLT-1 gene expression levels in the normotensive group ( $\mathrm{n}=32, r=-0.392, P=0.026$ ). In contrast mean methylation at CpG site 24 in the FLT-1 promoter region was positively associated with $F L T-1$ gene expression in the preterm PE group ( $\mathrm{n}=30, r=0.434, P=0.017)$. Further the mean methylation at $\mathrm{CpG}$ site 12.13 in the KDR promoter region was negatively associated with $K D R$ gene expression in the term PE group ( $\mathrm{n}=30, r=-0.369, P=0.045)$.

\section{Discussion}

In this study, we examined the $\mathrm{CpG}$ methylation of $V E G F, F L T-1$ and KDR gene promoters and their expression in human placentae. These genes encode important proteins that determine placental angiogenesis. This study shows several interesting findings: 1) some CpG sites in the promoter regions of these genes showed differential methylation between the normotensive, term and preterm PE groups; 2) mean promoter methylation in the VEGF gene was significantly lower in the preterm PE group compared to normotensive, while it was comparable between normotensive and term PE group; 3) VEGF expression was significantly higher in the preterm PE compared to the normotensive group, while it was lower in the term PE group; 4) although mean methylation in the FLT1 and $K D R$ promoters was similar between the three groups, FLT-1 and KDR gene expression was significantly higher in the preterm $\mathrm{PE}$ group compared to the term PE and the normotensive group; 5) mean methylation at the $V E G F$ promoter and methylation at some differentially methylated CpG sites in the VEGF and FLT-1 promoters was associated with term and preterm gestations, and 6) mean methylation at some differentially methylated CpG sites in the VEGF, FLT-1 and KDR promoters was associated with their gene expression levels.

DNA methylation is an important epigenetic mechanism of gene regulation. In the VEGF, FLT-1 and KDR promoter regions, some $\mathrm{CpG}$ sites were differentially methylated between the normotensive and PE groups. These results indicate possible involvement of altered DNA methylation patterns in these genes, which could be involved in the pathophysiology of PE. In humans, DNA methylation is mediated by DNA methyltransferases that are responsible for de novo methylation and maintenance of methylation patterns during replication. There is abundant evidence that suggests that DNA methylation patterns can be altered as a component of disease pathogenesis [29,30]. However, further studies are needed to determine the functional relevance of these findings in the pathophysiology of PE.

Alterations in methylation status within promoter regions can affect gene expression and hence the phenotype [31]. Our results show an increase in VEGF mRNA in preterm PE compared to term PE and normotensive placentas. It has been suggested that in severe PE, higher levels of placental hypoxia inducible transcription factors upregulate $V E G F$ expression [32]. Upregulation of $V E G F$ in preterm the PE placenta is suggestive of a compensatory mechanism attempting to normalize angiogenesis and blood flow. Furthermore, the VEGF promoter (mean 
promoter methylation) was significantly hypomethylated in the preterm PE group and this may be responsible for the increased expression of VEGF observed in this group. These results are consistent with other reports that suggest an inverse relationship between promoter CpG methylation and gene expression and indicate epigenetic control of VEGF expression in preterm PE [33,34]. It is also possible that the CpG sites 6.7, 8 and 14, which are differentially methylated in the preterm PE group compared to the normotensive group, may be involved in the upregulation of VEGF mRNA levels.

Although the mean methylation of the VEGF promoter was comparable between the normotensive and term PE group, the gene expression levels were significantly lower in the term PE group compared to the normotensive group. Generally, the pathology of preterm PE is regarded as more severe compared to term PE. Previous studies have suggested the existence of different subsets of PE and that pathophysiologic mechanisms may contribute differently to the development of preterm versus term PE $[35,36]$. It is likely that since term PE is less severe compared to preterm PE, the compensatory increase in VEGF mRNA levels is not observed, neither is there a difference in the promoter methylation levels. The observed decrease in VEGF expression in the term PE may be due to alternative pathways of gene expression regulation such as alterations in transcription factor expression or histone modifications as a consequence of the pathology. Some previous studies have also shown reduced placental VEGF mRNA levels at term in the PE compared to the normotensive group $[9,19]$.

Mean methylation of the $F L T-1$ and $K D R$ promoters was comparable between groups, yet the mRNA levels of FLT-1 and KDR were significantly higher in the preterm PE group compared to the other two groups. Although there was no difference in the mean promoter methylation in the FLT-1 gene promoter, CpG site 17 was significantly hypomethylated in the preterm $\mathrm{PE}$ group compared to the normotensive and term PE group. This site may be important in influencing the FLT-1 expression in preterm PE, however further studies are needed to determine the exact role of this site in the regulation of FLT-1 expression. Further KDR expression in preterm $P E$ may not be mediated through DNA methylation changes but through other factors affecting gene expression such as transcription factors, mRNA stability and histone modifications. Modulation of factors affecting gene expression by intracellular signals in different physiological states is well established. The opposite trends in VEGF, FLT-1 and $K D R$ mRNA levels and the difference in epigenetic patterns between these two groups provide further support for the existence of differences in pathology between term and preterm PE.
Our previous studies have established that omega 3 fatty acids and micronutrients (folic acid and vitamin $\mathrm{B}_{12}$ ) are interlinked in the one carbon cycle $[37,38]$. Further, we have also reported decreased omega 3 fatty acids and increased plasma homocysteine levels in preeclamptic mothers [26]. Since these pathways are major determinants of the methylation potential of the cell, our results could affect DNA methylation patterns, thereby influencing regulation of vital genes [39].

Further we attempted to understand the functional relevance of methylation changes by investigating whether the differentially methylated CpG sites in VEGF, FLT-1 and $K D R$ gene promoters were located within transcription factor binding sites. Although, few transcription factor binding sites were predicted in close proximity of the differentially methylated $\mathrm{CpG}$ sites in promoter regions of all three genes, it is difficult to assign importance to these changes. Further studies are needed to understand the role of methylation at these $\mathrm{CpG}$ sites in regulating the gene expression through transcription factor binding.

We observed that mean methylation of the VEGF promoter and some differentially methylated sites in the $V E G F$ and FLT-1 promoters were associated with term and preterm gestations. CpG 6.7 methylation in the VEGF promoter was negatively associated with term and preterm PE gestations. Methylation of CpG 16 in the FLT-1 promoter was positively associated with preterm PE gestation. Human pregnancy comprises a complex series of differentiation and growth processes that are spatio-temporally regulated [23]. We have previously reported gestationdependent changes in placental global DNA methylation [20]. Novakovic et al. (2009) have reported changes in promoter CpG methylation (both increase and decrease in methylation) with gestation in the placenta [40]. In addition to CpG sites that consistently change over gestation, they also report the existence of $\mathrm{CpG}$ sites that show inter-individual variability within each gestational age and suggest that such variability could be attributed to cumulative differences in environmental exposure.

Our results show that mean methylation of some of the differentially methylated sites in the VEGF, FLT-1 and KDR promoters were positively or negatively associated with their gene expression levels. Although hypermethylation is generally associated with suppression of gene expression, recent studies have also reported a positive association between methylation and gene expression [41-43].

\section{Conclusions}

To summarize, the CpG methylation patterns and expression of VEGF differs between the preterm PE and term PE group and could be causally related to the differences in pathology of term and preterm PE. We have previously reported altered one-carbon metabolism, hyperhomocysteinemia and increased oxidative stress in PE, which 
are known to influence DNA methylation patterns. Thus, our results could be attributed to these changes in the intrauterine environment. However, it is unclear whether the observed differences are a cause or effect of the underlying pathophysiology. Nevertheless, this study reiterates that CpG methylation is dynamic and influenced by the intrauterine environment. Further, as seen in the case of the VEGF gene, DNA methylation changes could account for the alterations in gene expression, and the ability to induce compensatory mechanisms to circumvent adverse pregnancy outcome. This study also highlights that DNA methylation may not explain all gene expression changes, and other mechanisms of gene expression regulation also come into play. The role of $\mathrm{CpG}$ methylation, in other regions in the gene also cannot be ruled out, since it has also been suggested that methylation changes in the gene body could also affect expression [44]. This study is the first account of CpG methylation changes in the VEGF, FLT-1 and $K D R$ gene promoters in pregnancies complicated by $\mathrm{PE}$.

\section{Methods}

\section{Subjects}

This study was conducted at the Department of Obstetrics and Gynecology, Bharati Hospital, Pune with the understanding and consent of each subject and was approved by the Bharati Vidyapeeth Medical College Institutional Ethical Committee. A total number of 139 pregnant women with singleton pregnancy were recruited for this study. Of these, 46 women had normotensive pregnancies and delivered at term, 93 women had PE during pregnancy, of which 45 delivered preterm ( $<37$ weeks), while 48 delivered at term ( $\geq 37$ weeks). Women were excluded from the study if there was evidence of other pregnancy complications, such as chronic hypertension, type 1 or type 2 diabetes mellitus, seizure disorder and renal or liver disease. All study participants neither consumed alcohol nor smoked and were from a low socioeconomic group.

The normotensive group consisted of pregnant women with no medical or obstetric complications. Pregnant women with eclampsia were excluded from the study. PE was diagnosed by an obstetrician who is also one of the investigators in this study (SSM) and PE has been discussed by us in a number of our earlier studies [45-47]. PE was defined by systolic and diastolic blood pressures greater than 140 and $90 \mathrm{~mm} \mathrm{Hg}$, respectively, with presence of proteinuria ( $>1+$ or $300 \mathrm{mg} / 24 \mathrm{hrs}$ ) on a dipstick test and was confirmed by repeated recording of the blood pressure with an interval of $6 \mathrm{hrs}$. Blood pressure was recorded frequently, starting at enrollment and at every follow up visit, which occurred approximately once a month until delivery. Response: Yes the preceding statement may be deleted. The data provided are the blood pressure values at the time of delivery, that is, just before going to the labor room, to ensure that a similar time point was used for both groups to rule out the effect on blood pressure of stress due to labor. Treatment of preeclamptic women included antihypertensive drugs and arginine supplementation. In severe PE cases, magnesium sulphate was given intravenously. Gestational age was based on the day of last menstrual period and was confirmed by ultrasound. All women were routinely given iron and folic acid supplements as per the National Anemia Prophylaxis Program.

\section{Tissue collection and processing}

Fresh placental tissues were obtained from normal and preeclamptic pregnancies immediately after delivery. Fetal membranes were trimmed off and small pieces were randomly cut out from the placental cotyledons. Tissue were rinsed in phosphate-buffered saline to wash off maternal and fetal blood, snap frozen in liquid nitrogen and stored at $-80^{\circ} \mathrm{C}$ until assayed.

\section{Gene promoter methylation assay}

Genomic DNA was isolated from placental samples using the DNeasy Blood and Tissue kit (Cat No. 69504, Qiagen, Hilden, Germany) using the protocol supplied by the manufacturer. One microgram of purified genomic DNA was bisulfite-treated using the EZ DNA Methylation ${ }^{\mathrm{TM}}$ Kit (Cat No. D5006, Zymo Research, California, USA) as per the manufacturer's instructions. The bisulfite-modified DNA was used for Sequenom MassARRAY EpiTYPING for gene-specific methylation analysis of VEGF, FLT-1, and $K D R$. In this technique, base-specific cleavage followed by MALDI-TOF mass spectrometry is used. The size ratio of the cleaved products provides quantitative methylation estimates for CpG sites within a target region. Genomic sequences for assay design were extracted from the UCSC genome browser (http://www.genome.ucsc.edu/). Primer pairs for amplification were designed using EpiDesigner web tool (http://www.epidesigner.com/). The promoter $\mathrm{CpG}$ island sequences used in this study for CpG methylation analysis of VEGF (Chromosome 6, 43737274 to 43737739), FLT-1 (Chromosome 13, 29067752 to 29068196) and KDR (Chromosome 4, 55991374 to 55991777) were selected using the UCSC genome browser and are given in Figure 5. For PCR amplification, a T7promoter tag was added to the reverse primer for performing the in vitro transcription, and a 10-mer tag sequence was added to the forward primer to balance the PCR primer length. The primers are listed in Table 3.

Bisulfite-treated genomic DNA was amplified using the designed primers. The thermal cycling conditions were as follows. For the VEGF- 1 cycle: $95^{\circ} \mathrm{C}$ for 15 minutes; 5 cycles: $95^{\circ} \mathrm{C}$ for 1 minutes, $62^{\circ} \mathrm{C}$ for 2 minutes, $72^{\circ} \mathrm{C}$ for 2 minutes; 32 cycles: $95^{\circ} \mathrm{C}$ for 1 minute, $62^{\circ} \mathrm{C}$ for 1 minute, $72^{\circ} \mathrm{C}$ for 1 minute then $72^{\circ} \mathrm{C}$ for 7 minutes. For the $F L T-1$ and $K D R-1$ cycle: $95^{\circ} \mathrm{C}$ for 15 minutes; 5 cycles: $95^{\circ} \mathrm{C}$ for 1 


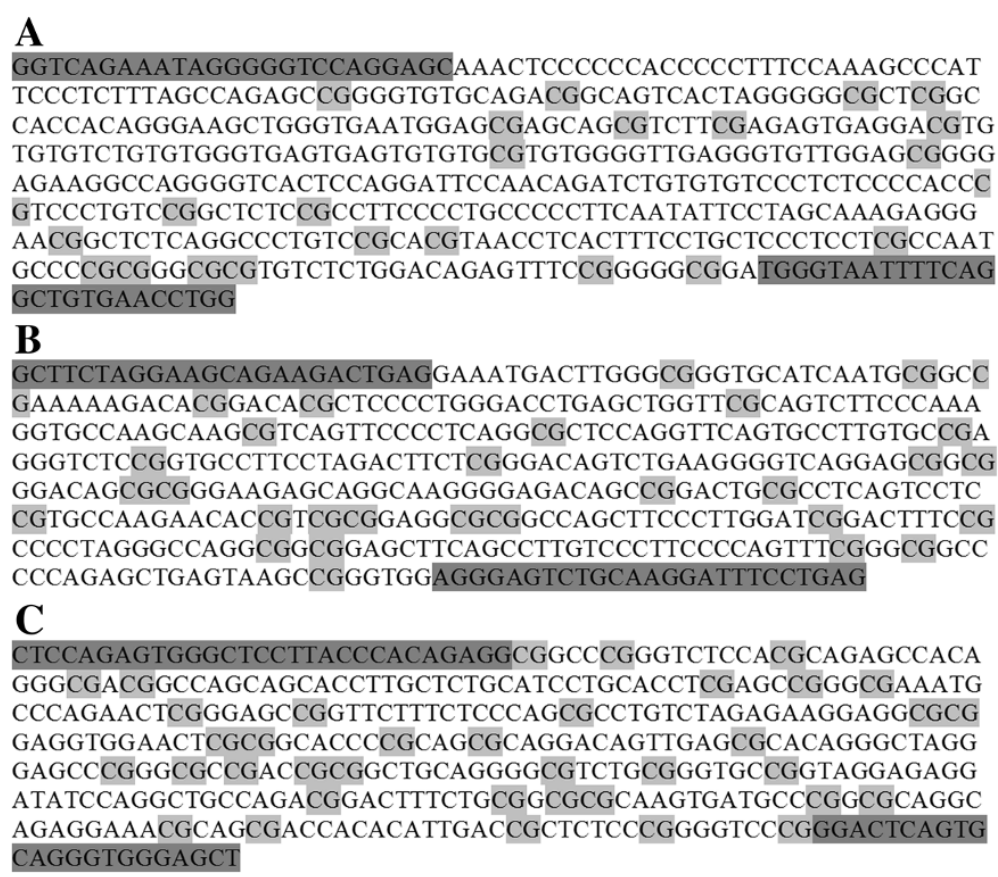

Figure 5 Promoter sequences selected for analysis of CpG methylation of (A) VEGF (B) FLT-1 and (C) KDR genes. Sequences highlighted in dark gray indicate primers. Sequences highlighted in light gray indicate CpG sites analyzed.

minute, $60^{\circ} \mathrm{C}$ for 2 minutes, $72^{\circ} \mathrm{C}$ for 2 minutes; 35 cycles: $95^{\circ} \mathrm{C}$ for 1 minutes, $60^{\circ} \mathrm{C}$ for 1 minute, $72^{\circ} \mathrm{C}$ for 1 minute then $72^{\circ} \mathrm{C}$ for 7 minute.

Following PCR amplification, in vitro transcription and T-cleavage assay was performed using MassCLEAVE ${ }^{\mathrm{ma}}$ Reagent Kit (Cat No. 10129, Sequenom). Unincorporated dinucleotide triphosphates were removed by shrimp alkaline phosphatase treatment. Typically, $2 \mu \mathrm{l}$ of the PCR product was directly used as template for the in vitro transcription reaction. T7 RNA and DNA polymerase was used to incorporate thymidine triphosphate in the transcripts. In the same step, RNase-A was added to cleave the in vitro transcripts (T-cleavage assay). Samples were diluted with $20 \mu \mathrm{l}$ of water. Conditioning of the phosphate backbone was done by adding $6 \mathrm{mg}$ of Clean Resin before performing MALDI-TOF mass spectrometry (MS) analysis. For MS analysis RNase-A-treated product was robotically dispensed onto silicon matrix preloaded chips (SpectroCHIP Cat No. 10117, Sequenom), and the mass spectra were collected using a MassARRAY Compact MALDI-TOF (Sequenom). Methylation data were generated as $\beta$ values between 0 and 1 , indicating percentage methylation of the original template. The methylation ratios were generated from the spectra by the EpiTYPER software v1.0 (Sequenom, California, USA).

Samples that yielded data in greater than $70 \%$ for all CpG units within a promoter were passed for that sample/ promoter pair. For each sample the methylation analysis was done in duplicates and sites showing more than $10 \%$ difference in methylation were excluded. Sites that were tagged as low mass or high mass by Epityper software were also excluded from the analysis. We attempted to predict

Table 3 Primers used for promoter CpG analysis

\begin{tabular}{|c|c|c|c|}
\hline Primer code & Primer sequence $\left(5^{\prime}-3^{\prime}\right)^{*}$ & $\begin{array}{l}\text { Amplicon length } \\
\text { (base pairs) }\end{array}$ & Number of $\mathrm{CpG}$ sites analyzed \\
\hline VEGF_F1 & aggaagagagTTAGAAATAGGGGGTTTAGGAGTAAAT & \multirow[t]{2}{*}{465} & \multirow[t]{2}{*}{23} \\
\hline VEGF_R1 & cagtaatacgactcactatagggagaaggctCCAAATTCACAACCTAAAAATTACCCA & & \\
\hline FLT1_F1 & aggaagagagGTIITAGGAAGTAGAAGATTGAGG & \multirow[t]{2}{*}{444} & \multirow[t]{2}{*}{30} \\
\hline FLT1_R1 & cagtaatacgactcactatagggagaaggctCTCAAAAAATCCTTACAAACTCCCT & & \\
\hline KDR_F1 & aggaagagagTTTAGAGTGGGTITTTATTTATAGAGG & \multirow[t]{2}{*}{403} & \multirow[t]{2}{*}{37} \\
\hline KDR_R1 & cagtaatacgactcactatagggagaaggctAACTCCCACCCTACACTAAATCC & & \\
\hline
\end{tabular}

* T7-promoter sequence tag -cagtaatacgactcactatagggagaaggct added to reverse primer.

10-mer sequence tag- aggaagagag added to the forward primer. 
the transcription factor binding sites in the VEGF, FLT-1 and $K D R$ promoter regions using the transcription factor binding site predictor tool, PROMO (version 3.0.2) (http:// alggen.lsi.upc.es/cgi-bin/promo_v3/promo/promoinit. cgi?dirDB=TF_8.3) $[48,49]$.

\section{Extraction of total RNA, cDNA synthesis and quantitative real-time (RT)-PCR assays}

Total RNA from placenta samples was isolated using the Trizol method and quantified by the Nanodrop (ND1000 v3.5.2) spectrophotometer. One microgram of total RNA was transcribed to cDNA using the High-Capacity cDNA reverse transcription Kit (Cat No. 4368814, Applied Biosystems, California, USA). RT-quantitative (q)-PCR for VEGF, FLT-1, KDR mRNAs, and 18S rRNA were performed with the TaqMan Universal PCR Master Mix (Cat No. 4324018, Applied Biosystems, California, USA) using the Applied Biosystems 7500 FAST system. The relative expression level of the gene of interest was examined with respect to $18 \mathrm{~S}$ rRNA to normalize for variation in the quality of RNA and the amount of input cDNA. The RT-PCR reactions for each gene were performed in duplicate. To analyze the RT-PCR results, the average cycle number $(\mathrm{Ct})$ of the reaction when it crossed a threshold valued was determined for each reaction. Differences in $\mathrm{Ct}(\Delta \mathrm{Ct})$ between $18 \mathrm{~S}$ and the targeted gene were calculated by subtracting the $\mathrm{Ct}$ of the targeted gene from $\mathrm{Ct}$ of $18 \mathrm{~S}$. Relative expression levels of genes were calculated and expressed as $2^{\Delta \mathrm{Ct}}$. The following TaqMan ${ }^{\circledR}$ Gene Expression Assays (Applied Biosystems, California, USA) were used in this study: 18S RNA (Hs99999901_s1); VEGF (Hs00900058_m1); FLT-1 (Hs01052936_m1); KDR (Hs00176676_m1).

\section{Statistical analysis}

Data were analyzed using SPSS/PC + package (Version 20.0, Chicago, IL, USA). Values are reported as mean \pm SD (demographic characters) or mean \pm standard error (SE) (gene expression and methylation studies). Mean values of the estimates were compared using one-way ANOVA and the post hoc least significant difference (LSD) test at conventional levels of significance $(P<0.05)$. Skewed variables were transformed to normality using log to the base 10. The extent of the linear relationship between several variables was studied using bivariate correlation analysis.

\section{Additional files}

Additional file 1: (A) Mean percent methylation at each CpG site in the VEGF promoter. ${ }^{*} P<0.05$, ${ }^{* *} P<0.01$ as compared to control. $P E$, preeclampsia; (B) Mean percent methylation at each CpG site in the FLT-1 promoter. ${ }^{*} \mathrm{P}<0.05,{ }^{* *} \mathrm{P}<0.01$ as compared to control; @ $\mathrm{P}<0.05$ as compared to Term PE. PE, preeclampsia; (C) Mean percent methylation at each CPG site in the KDR promoter. * $\mathrm{P}<0.05$ as compared to control. PE, preeclampsia.

Additional file 2: Transcription factor binding sites predicted in the promoter region of (a) VEGF (b) FLT-1 and (c) KDR genes.

\section{Abbreviations}

ANOVA: Analysis of variance; Ct: Average cycle number; FLT-1: fms-like tyrosine kinase-1; KDR: Kinase insert domain containing receptor; LSD: Least significant difference; MS: Mass spectrometry; PCR: Polymerase chain reaction; PE: Preeclampsia; RT-PCR: Real-time polymerase chain reaction; SE: Standard error; VEGF: Vascular endothelial growth factor; VEGFR: Vascular endothelial growth factor receptor.

\section{Competing interests}

The authors declare that they have no competing interests.

\section{Authors' contributions}

SRJ and SSM conceived and designed the experiments. DPS, USR, AAJ, PMCG and GRC performed the experiments. DPS, USR, AAJ, PMCG, SRJ and GRC analyzed the data. SSM, AAH and GRC contributed reagents/materials/ analysis tools. PMCG, DPS, AAJ and SRJ wrote the paper. All authors read and approved the final manuscript.

\section{Acknowledgement}

The authors thank the Indian Council of Medical Research (ICMR), India (No. 5/7/536/11) and the Council of Scientific and Industrial Research (CSIR), Ministry of Science and Technology, Govt of India (Network project "EpiHeD" under XIIth FYP) for providing funds for the epigenetic studies. The authors also thank all the subjects who volunteered in this study and nurses of Bharati Hospital who helped in collecting the samples.

\section{Author details}

${ }^{1}$ Department of Nutritional Medicine, Interactive Research School for Health Affairs, Bharati Vidyapeeth University, Pune 411043, India. ${ }^{2}$ Department of Obstetrics and Gynecology, Bharati Medical College and Hospital, Bharati Vidyapeeth University, Pune 411043, India. ${ }^{3}$ Centre for Cellular and Molecular Biology, Council of Scientific and Industrial Research (CSIR), Hyderabad 500007, India. ${ }^{4}$ Diabetes and Islet-biology Group, NHMRC Clinical Trials Centre, The University of Sydney, Camperdown, NSW 2050, Australia.

Received: 31 December 2012 Accepted: 5 April 2013 Published: 26 April 2013

\section{References}

1. Noori M, Donald AE, Angelakopoulou A, Hingorani AD, Williams DJ: Function before and after preeclampsia and gestational hypertension prospective study of placental angiogenic factors and maternal vascular function before and after preeclampsia and gestational hypertension. Circulation 2010, 122:478-487.

2. Zhou Y, McMaster M, Woo K, Janatpour M, Perry J, Karpanen T, Alitalo K, Damsky C, Fisher SJ: Vascular endothelial growth factor ligands and receptors that regulate human cytotrophoblast survival are dysregulated in severe preeclampsia and hemolysis, elevated liver enzymes, and low platelets syndrome. Am J Pathol 2002, 160:1405-1423.

3. Holash J, Davis S, Papadopoulos N, Croll SD, Ho L, Russell M, Boland P, Leidich R, Hylton D, Burova E, loffe E, Huang T, Radziejewski C, Bailey K, Fandl JP, Daly T, Wiegand SJ, Yancopoulos GD, Rudge JS: VEGF-Trap: a VEGF blocker with potent antitumor effects. Proc Natl Acad Sci USA 2002, 99:1393-1398

4. Kumazaki K, Nakayama M, Suehara N, Wada Y: Expression of vascular endothelial growth factor, placental growth factor, and their receptors Flt-1 and KDR in human placenta under pathologic conditions. Hum Pathol 2002, 33:1069-1077.

5. Munaut $C$, Lorquet S, Pequeux C, Blacher S, Berndt S, Frankenne F, Foidart JM: Hypoxia is responsible for soluble vascular endothelial growth factor receptor-1 (VEGFR-1) but not for soluble endoglin induction in villous trophoblast. Hum Reprod 2008, 23:1407-1415. 
6. Lee GS, Joe YS, Kim SJ, Shin JC: Cytokine-related genes and oxidationrelated genes detected in preeclamptic placentas. Arch Gynecol Obstet 2010, 282:363-369

7. Kweider N, Fragoulis A, Rosen C, Pecks U, Rath W, Pufe T, Wruck CJ: Interplay between vascular endothelial growth factor (VEGF) and nuclear factor erythroid 2-related factor-2 (Nrf2): implications for preeclampsia. J Biol Chem 2011, 286:423863-423872.

8. Lyall F, Young A, Boswell F, Kingdom JC, Greer IA: Placental expression of vascular endothelial growth factor in placentae from pregnancies complicated by pre-eclampsia and intrauterine growth restriction does not support placental hypoxia at delivery. Placenta 1997 18:269-276

9. Cooper JC, Sharkey AM, Charnock-Jones DS, Palmer CR, Smith SK: VEGF mRNA levels in placentae from pregnancies complicated by preeclampsia. Br J Obstet Gynaecol 1996, 103:1191-1196.

10. Kim SC, Park MJ, Joo BS, Joo JK, Suh DS, Lee KS: Decreased expressions of vascular endothelial growth factor and visfatin in the placental bed of pregnancies complicated by preeclampsia. J Obstet Gynaecol Res 2012, 38:665-673.

11. Toft JH, Lian IA, Tarca AL, Erez O, Espinoza J, Eide IP, Bjørge L, Draghici S, Romero R, Austgulen R: Whole-genome microarray and targeted analysis of angiogenesis regulating gene expression (ENG, FLT1, VEGF, PIGF) in placentas from pre-eclamptic and small-for-gestational-age pregnancies. J Matern Fetal Neonatal Med 2008, 21:267-273.

12. Ranheim T, Staff AC, Henriksen T: VEGF mRNA is unaltered in decidual and placental tissues in preeclampsia at delivery. Acta Obstet Gynecol Scand 2001, 80:93-98.

13. Sgambati E, Marini M, Zappoli Thyrion GD, Parretti E, Mello G, Orlando C, Simi L, Tricarico C, Gheri G, Brizzi E: VEGF expression in the placenta from pregnancies complicated by hypertensive disorders. Br J Obstet Gynaecol 2004, 111:564-570.

14. Heydarian M, McCaffrey T, Florea L, Yang Z, Ross MM, Zhou W, Maynard SE: Novel splice variants of sFlt1 are upregulated in preeclampsia. Placenta 2009, 30:250-255.

15. Rajakumar A, Powers RW, Hubel CA, Shibata E, von Versen-Höynck F, Plymire D, Jeyabalan A: Novel soluble Flt-1 isoforms in plasma and cultured placental explants from normotensive pregnant and preeclamptic women. Placenta 2009, 30:25-34.

16. Munaut C, Lorquet S, Pequeux C, Coulon C, Le Goarant J, Chantraine F, Noël A, Goffin F, Tsatsaris V, Subtil D, Foidart JM: Differential expression of Vegfr-2 and its soluble form in preeclampsia. PLoS One 2012, 7:e33475.

17. Tripathi R, Rath G, Jain A, Salhan S: Soluble and membranous vascular endothelial growth factor receptor-1 in pregnancies complicated by pre-eclampsia. Ann Anat 2008, 90:477-489.

18. Helske $S$, Vuorela P, Carpén O, Hornig C, Weich H, Halmesmäki E: Expression of vascular endothelial growth factor receptors 1, 2 and 3 in placentas from normal and complicated pregnancies. Mol Hum Reprod 2001, 7:205-210.

19. Andraweera PH, Dekker GA, Laurence JA, Roberts CT: Placental expression of VEGF family mRNA in adverse pregnancy outcomes. Placenta 2012, 33:467-472.

20. Chavan-Gautam P, Sundrani D, Pisal H, Nimbargi V, Mehendale S, Joshi S: Gestation-dependant changes in human placental global DNA methylation levels. Mol Reprod Dev 2011, 78:150.

21. Hales CN, Barker DJ: The thrifty phenotype hypothesis. Br Med Bull 2001, 60:5-20.

22. Oyama S: The ontogeny of information. In Developmental systems and evolution. 2nd edition. Raleigh, NC: Duke University Press; 2000.

23. Lins RJ, Mitchell MD: Novel insights into the control of human pregnancy: potential role(s) for epigenetic regulation. Reproductive Biology Insights 2008, 1:3-8.

24. Zhang Y, Cui Y, Zhou Z, Sha J, Li Y, Liu J: Altered global gene expressions of human placentae subjected to assisted reproductive technology treatments. Placenta 2010, 31:251-258.

25. Alegría-Torres JA, Baccarelli A, Bollati V: Epigenetics and lifestyle. Epigenomics 2011, 3:267-277.

26. Kulkarni A, Mehendale S, Pisal H, Kilari A, Dangat K, Salunkhe S, Taralekar V, Joshi S: Association of omega 3 fatty acids and homocysteine concentrations in pre-eclampsia. Clin Nutr 2011, 30:60-64.
27. Kulkarni A, Chavan-Gautam P, Mehendale S, Yadav H, Joshi S: Global DNA methylation patterns in placenta and its association with maternal hypertension in pre-eclampsia. DNA Cell Biol 2011, 30:79-84

28. Dhobale M, Chavan P, Kulkarni A, Mehendale S, Pisal H, Joshi S: Reduced folate, increased vitamin $\mathrm{B}_{12}$ and homocysteine concentrations in women delivering preterm. Ann Nutr Metab 2012, 61:7-14.

29. van Vliet J, Oates NA, Whitelaw E: Epigenetic mechanisms in the context of complex diseases. Cell Mol Life Sci 2007, 64:1531-1538.

30. Abdolmaleky HM, Cheng KH, Faraone SV, Wilcox M, Glatt SJ, Gao F, Smith $\mathrm{CL}$, Shafa R, Aeali B, Carnevale J, Pan H, Papageorgis P, Ponte JF, Sivaraman $V$, Tsuang MT, Thiagalingam S: Hypomethylation of MB-COMT promoter is a major risk factor for schizophrenia and bipolar disorder. Hum Mol Genet 2006, 15:3132-3145.

31. Ball MP, Li JB, Gao Y, Lee JH, LeProust EM, Park IH, Xie B, Daley GQ, Church GM: Targeted and genome-scale strategies reveal gene-body methylation signatures in human cells. Nat Biotechnol 2009, 27:361-368

32. Torry DS, Torry RJ: Angiogenesis and the expression of vascular endothelial growth factor in endometrium and placenta. Am J Reprod Immunol 1997, 37:21-29.

33. Sun Z, Asmann YW, Kalari KR, Bot B, Eckel-Passow JE, Baker TR, Carr JM, Khrebtukova I, Luo S, Zhang L, Schroth GP, Perez EA, Thompson EA: Integrated Analysis of Gene Expression, CpG Island Methylation, and Gene Copy Number in Breast Cancer Cells by Deep Sequencing. PLoS One 2011, 6:e17490

34. Reik W: Stability and flexibility of epigenetic gene regulation in mammalian development. Nature 2007, 447:425-432.

35. Roberts JM, Catov JM: Preeclampsia more than 1 disease: or is it? Hypertension 2008, 51:989-990.

36. Phillips JK, Janowiak M, Badger GJ, Bernstein IM: Evidence for distinct preterm and term phenotypes of preeclampsia. J Matern Fetal Neonatal Med 2010, 23:622-626

37. Kale A, Naphade N, Sapkale S, Kamaraju M, Pillai A, Joshi S, Mahadik S: Reduced folic acid, vitamin $B_{12}$ and docosahexaenoic acid and increased homocysteine and cortisol in nevermedicated schizophrenia patients: implications for altered one-carbon metabolism. Psychiatry Res 2010, 175:47-53.

38. Kulkarni A, Dangat K, Kale A, Sable P, Chavan-Gautam P, Joshi S: Effects of altered maternal folic acid, vitamin $B_{12}$ and docosahexaenoic acid on placental global DNA methylation patterns in wistar rats. PLoS One 2011, 6:e17706.

39. Sharma RP: Schizophrenia, epigenetics and ligand-activated nuclear receptors: a framework for chromatin therapeutics. Schizophr Res 2005 72:79-90.

40. Novakovic B, Sibson M, Ng HK, Manuelpillai U, Rakyan V, Down T, Beck S, Fournier T, Evain-Brion D, Dimitriadis E, Craig JM, Morley R, Saffery R: Placenta-specific methylation of the vitamin D 24-hydroxylase gene: implications for feedback autoregulation of active vitamin D levels at the fetomaternal interface. J Biol Chem 2009, 284:14838-14848.

41. Bell JT, Pai AA, Pickrell JK, Gaffney DJ, Pique-Regi R, Degner JF, Gilad Y, Pritchard JK: DNA methylation patterns associate with genetic and gene expression variation in HapMap cell lines. Genome Biol 2011, 12:R10.

42. Gibbs JR, van der Brug MP, Hernandez DG, Traynor BJ, Nalls MA, Lai SL, Arepalli S, Dillman A, Rafferty IP, Troncoso J, Johnson R, Zielke HR, Ferrucc $L$, Longo DL, Cookson MR, Singleton AB: Abundant quantitative trait loci exist for DNA methylation and gene expression in human brain. PLoS Genet 2010, 6:e1000952.

43. Zhang D, Cheng L, Badner JA, Chen C, Chen Q, Luo W, Craig DW, Redman M, Gershon ES, Liu C: Genetic control of individual differences in genespecific methylation in human brain. Am J Hum Genet 2010, 86:411-419.

44. Maunakea AK, Nagarajan RP, Bilenky M, Ballinger TJ, D'souza C, Fouse SD, Johnson BE, Hong C, Nielsen C, Zhao Y, Turecki G, Delaney A, Varhol R, Thiessen N, Shchors K, Heine VM, Rowitch DH, Xing X, Fiore C, Schillebeeckx M, Jones SJ, Haussler D, Marra MA, Hirst M, Wang T, Costello JF: Conserved role of intragenic DNA methylation in regulating alternative promoters. Nature 2010, 466:253-257.

45. Kulkarni AV, Mehendale SS, Yadav HR, Kilari AS, Taralekar VS, Joshi SR: Circulating angiogenic factors and their association with birth outcomes in preeclampsia. Hypertens Res 2010, 33:561-567. 
46. Kilari A, Mehendale S, Pisal H, Panchanadikar T, Kale A, Joshi S: Nerve growth factor, birth outcome and pre-eclampsia. Int J Dev Neurosci 2011, 29:71-75.

47. Dangat K, Kilari A, Mehendale S, Lalwani S, Joshi S: Higher levels of brain derived neurotrophic factor but similar nerve growth factor in human milk in women with preeclampsia. Int J Dev Neurosci 2013, 31:209-213.

48. Messeguer X, Escudero R, Farré D, Nuñez O, Martínez J, Albà MM: PROMO: detection of known transcription regulatory elements using speciestailored searches. Bioinformatics 2002, 18:333-334.

49. Farré $D$, Roset $R$, Huerta $M$, Adsuara JE, Roselló L, Albà MM, Messeguer X: Identification of patterns in biological sequences at the ALGGEN server: PROMO and MALGEN. Nucleic Acids Res 2003, 31:3651-3653.

doi:10.1186/1868-7083-5-6

Cite this article as: Sundrani et al:: Differential placental methylation and expression of VEGF, FLT-1 and KDR genes in human term and preterm preeclampsia. Clinical Epigenetics 2013 5:6.

\section{Submit your next manuscript to BioMed Central and take full advantage of:}

- Convenient online submission

- Thorough peer review

- No space constraints or color figure charges

- Immediate publication on acceptance

- Inclusion in PubMed, CAS, Scopus and Google Scholar

- Research which is freely available for redistribution 